\title{
P01-030 - Proteinuria in FMF - prediction of nephropathy type
}

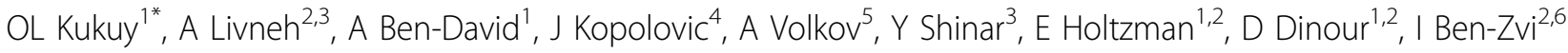 \\ From 7th Congress of International Society of Systemic Auto-Inflammatory Diseases (ISSAID) \\ Lausanne, Switerland. 22-26 May 2013
}

\section{Introduction}

Reactive (AA) amyloidosis may complicate Familial Mediterranean fever (FMF), the prototype of autoinflammatory diseases. Thus, proteinuria in FMF is commonly viewed as resulting from amyloidosis and kidney biopsy is deemed superfluous. However, nephropathy other than amyloidosis has been described in FMF, but its rate and distinctive characteristics are unknown.

\section{Objectives}

To determine the rate and underlying pathology of FMF related non-amyloidotic proteinuria and compare its clinical course, demographic and genetic features to those of FMF-amyloid nephropathy.

\section{Methods}

This study is a retrospective analysis of data from all FMF patients, undergoing kidney biopsy for proteinuria above 0.5 gram $/ 24$ hrs, during 10 years (2001- 2011). Clinical, laboratory, genetic and pathology data were abstracted from patient files. Biopsies were viewed by an experienced pathologist, as necessary.

\section{Results}

From 27 patients referred to kidney biopsy, only 16 (59.3\%) were diagnosed with amyloid kidney disease (AKD), 11 were diagnosed with another nephropathy. The AKD and non amyloid kidney disease (NAKD) groups were comparable on most variables, but showed distinct characteristics with regard to the range of proteinuria $(6.46 \pm 4.3 \mathrm{~g}$ vs. $2.4 \pm 1.7 \mathrm{~g}, \mathrm{p}=0.0136)$, rate of severe FMF (14 vs. 5 patients, $\mathrm{p}=0.03$ ) and rate of development of end stage renal disease $(75 \%$ vs. $27.2 \%, \mathrm{p}=0.02)$ respectively.

Institute of Nephrology and Hypertension, Sheba Medical Center, Tel Hashomer, Ramat Gan, Israel

Full list of author information is available at the end of the article

\section{Conclusion}

NAKD is common in FMF and is featured with milder course and better prognosis. Contrary to common practice, it is highly suggested to obtain kidney biopsy from patients with FMF and proteinuria more than $0.5 \mathrm{gr} /$ 24 hrs.

\section{Disclosure of interest}

None declared.

\section{Authors' details}

'Institute of Nephrology and Hypertension, Sheba Medical Center, Tel Hashomer, Ramat Gan, Israel. ${ }^{2}$ Sackler Faculty of Medicine, Tel Aviv University, Tel Aviv, Israel. ${ }^{3}$ Heller Institute of Medical Research, Sheba Medical Center, Tel Hashomer, Ramat Gan, Israel. ${ }^{4}$ Department of Pathology, Hadassah-Hebrew University Medical Center, Jerusalem, Israel. ${ }^{5}$ Department of Pathology, Sheba Medical Center, Tel Hashomer, Israel. ${ }^{6}$ Heller Institute of Medical Research, Sheba Medical Center, Tel Hashomer, Ramat Gan, Israel.

Published: 8 November 2013

doi:10.1186/1546-0096-11-S1-A34

Cite this article as: Kukuy et al:: P01-030 - Proteinuria in FMF -

prediction of nephropathy type. Pediatric Rheumatology 201311 (Suppl 1):A34.

Submit your next manuscript to BioMed Central and take full advantage of:

- Convenient online submission

- Thorough peer review

- No space constraints or color figure charges

- Immediate publication on acceptance

- Inclusion in PubMed, CAS, Scopus and Google Scholar

- Research which is freely available for redistribution
C Biomed Central

C 2013 Kukuy et al; licensee BioMed Central Ltd. This is an Open Access article distributed under the terms of the Creative Commons Attribution License (http://creativecommons.org/licenses/by/2.0), which permits unrestricted use, distribution, and reproduction in any medium, provided the original work is properly cited. 